\title{
COMBINED IRSL/OSL DATING ON FINE GRAINS FROM LAKE BAIKAL SEDIMENTS
}

\author{
PIOTR MOSKA, GRZEGORZ PORĘBA, ANDRZEJ BLUSZCZ and AGNIESZKA WISZNIOWSKA \\ Department of Radioisotopes, Institute of Physics, Silesian University of Technology, \\ Krzywoustego 2, 44-100 Gliwice, Poland
}

\begin{abstract}
In this work we present luminescence dating results obtained for samples taken from a gravity core of sediments of the Lake Baikal. The initial attempts to date coarse quartz grains failed because such grains were very sparse and dim. Fine grain quartz was also relatively dim and only IRSL signal from fine grain polymineral fraction was sufficient to obtain absorbed dose estimates. We made the measurements on 6-12 $\mu \mathrm{m}$ fraction extracted by differential precipitation in a water column. Samples were collected from the sediment depth range between $80-750 \mathrm{~cm}$ which, basing on paleomagnetic data, were expected to cover the period up to ca. $150 \mathrm{ka}$. The equivalent absorbed doses measured by means of OSL grow with depth down to $350 \mathrm{~cm}$ where they reach about 100-120 Gy and then apparently saturate. For the depth range $80-350 \mathrm{~cm}$ IRSL ages also grow almost linearly from 11 to $50 \mathrm{ka}$. Calibrated radiocarbon ages obtained for micro samples of pollen from the same site yielded an average sedimentation rate of $6.86 \pm 0.21 \mathrm{~cm} / \mathrm{ka}$ for the period between $15-1 \mathrm{ka}$ BP. This is in good agreement with the sedimentation rate deduced from IRSL dating $(6.15 \pm 0.55)$.
\end{abstract}

Keywords: IRSL/OSL dating, fine grains, Lake Baikal, Last climate cycle.

\section{INTRODUCTION}

In recent years, Lake Baikal has become the focus of several large-scale international research projects with the aim of reconstructing the climatic conditions over time in that region. The position of the lake in Central Asia and the presence of well stratified sediments which span millions of years offers an excellent opportunity to investigate a range of climate processes in a relatively unexplored world region (Colman et al., 1995; Karabanov et al., 2000a,b; Catto et al., 2001; Prokopenko et al., 2001). The lake is close to the boundaries of two important climatic systems - the Siberian high-pressure zone and monsoon zone. Lake Baikal is the world's largest freshwater lake and contains a long sediment archive suitable for tracing past and recent climate changes in Eurasia (Prokopenko et al., 2001a,b,c). Among the lakes, the Lake Baikal sedimentary record provides a good climate archive (Minoura, 2000). The lake is the deepest and one of the oldest on Earth, with about $7.5 \mathrm{~km}$ of sediments dating back to the Middle Eocene (Hutchinson et al.,

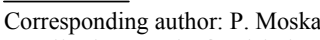

e-mail: Piotr.Moska@polsl.pl

ISSN 1897-1695 (online), 1733-8387 (print) (C) 2008 GADAM Centre,

Institute of Physics, Silesian University of Technology.

All rights reserved.
1992). It is isolated within the Asian continent and is far from any direct influence from oceans and ice sheets. Paleoclimate studies on Baikal have been intensified through the Baikal Drilling Program (BDP) (Kuzmin et al., 1993). So far, materials obtained from the Baikal Drilling Project have been used as a base for such reconstructions over a period of several million years. Data on lithology, sedimentology and dating results of the $600 \mathrm{~m}$ long core has been already published (Kuzmin et al., 2000).

The work undertaken in the Gliwice Luminescence Laboratory is part of an international research project "CONTINENT" aimed specifically at high resolution reconstruction of climatic conditions in the Holocene and Eemian periods. A number of gravitational cores have been obtained from different locations on the lake to provide undisturbed sediment records covering the last ca. $150 \mathrm{ky}$. Different climate parameters may be deduced from organic and inorganic components of the deposited matter. Optically stimulated luminescence dating (OSL) is one of the methods selected for dating Lake Baikal sediments and the only capable to provide absolute dating for the Eemian period. 
Luminescence dating is based on the premise that several naturally occurring minerals (e.g. quartz and feldspar) can be used as dosimeters, recording the amount of radiation to which they have been exposed (Murray and Olley, 2002). OSL dating is based on specific properties of quartz and feldspars that depend on the existence of defects within mineral crystals and the interaction of electrons with these defects (Duller, 2004). When the mineral is exposed to ionising radiation, some electrons are ejected from their usual states and some of these subsequently become trapped at specific defects referred to as traps. This is a metastable situation, but it is possible for the lifetime of a trapped electron to exceed $10^{8}$ years at ambient temperatures. This trapped-charge population increases with burial time in a measurable and predictable way. As a result, the time elapsed since sediment grains were buried can be determined by measuring both the total OSL signal and sensitivity from a sample of sediment, and by estimating the intensity of ionising radiation to which it has been exposed since burial. Establishing the OSL age of deposition requires different kinds of measurements. The dose rate and equivalent dose $(E D)$ have to be calculated. The dose rate depends on sample's radioactivity and water content, on the grain size and on amount of grain material removed during etching. Usually cosmic rays contribute also to the dose received by grains, and this contribution depends on geographic coordinates, altitude and burial depth. In case of Lake Baikal sediments, covered additionally by several hundred meters of water, the cosmic ray contribution becomes negligible. The equivalent dose is estimated from OSL measurements on minerals extracts before and after irradiating grains with known laboratory doses.

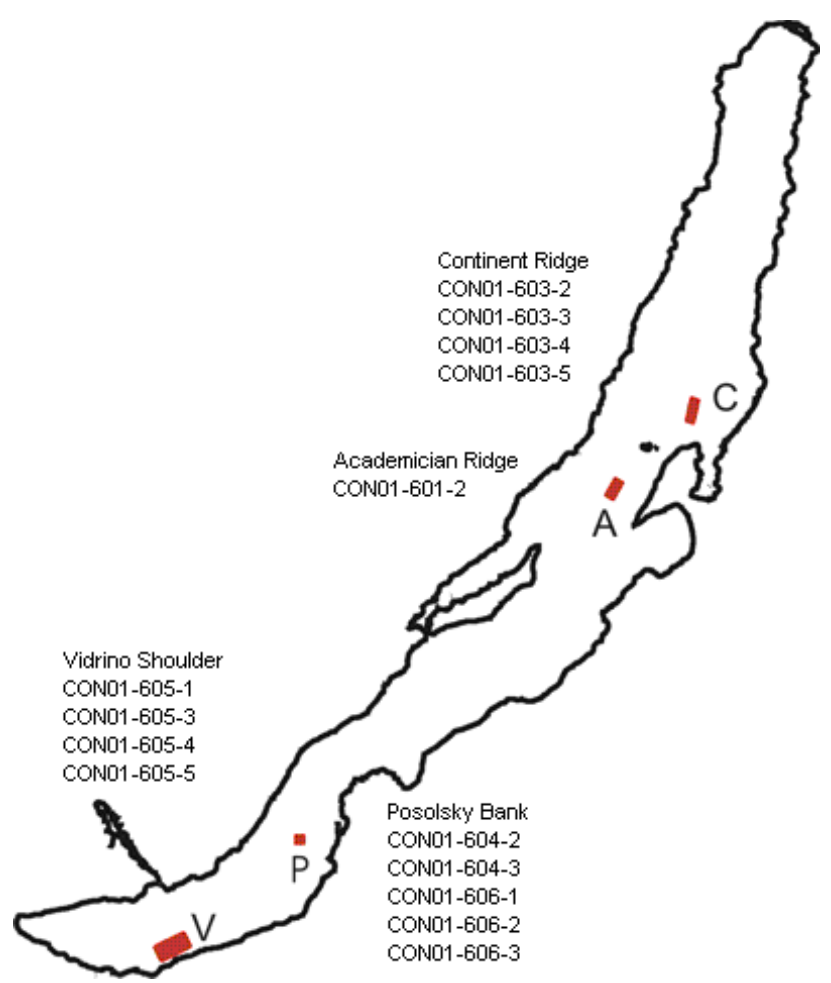

Fig. 1. Location of coring sites and core names. Samples from the Continent Ridge sites (C) were use din the present study.
In this work we present luminescence dating results obtained on samples taken from the gravity core CON01 603-4 of Lake Baikal sediments. Fig. 1 shows the places where the cores were taken.

The core CON01 603-4 was $1025 \mathrm{~cm}$ long and was divided into 11 sections. Sections are numbered from CON01 603-4 0001 (the oldest section, bottom part of the core) to CON01 603-4 0011 (the youngest section). Sections of the core CON01 603-4 were opened in a room with red light, and cut into two half-sections. Each halfsection was then divided into 5-cm long samples numbered continuously in the order of sampling. Sub-samples of a volume of a few $\mathrm{cm}^{3}$ were taken for water content measurements. After drying, gamma spectra were taken for at least 24 hours. Radioactivities of isotopes present in the sediment were calculated by comparing the gamma spectrum recorded for the sample with the spectrum recorded for the radioactivity standard and for the detector background. Dose rates were calculated basing on laboratory high-resolution gamma spectrometry analyses of about $200 \mathrm{~g}$ bulk samples of the sediment and using the conversion factors of Adamiec and Aitken (1998).

\section{FINE GRAIN EXTRACTION}

The initial attempts to date coarse quartz grains failed because such grains were very sparse and dim. Generally OSL single aliquot regenerative (SAR) results obtained for processed samples were of poor quality. This was due to several factors, mainly very low abundance of quartz grains of suitable size (100 $\mu \mathrm{m}$ and more) and very low sensitivity of these grains - measured OSL signal intensities were surprisingly low. Another difficult problem was the scatter of results indicating insufficient bleaching of most grains during their deposition, also in some samples contamination with feldspar could not be removed by chemical treatment (probably feldspar occurred within quartz grains).

Because of the above mentioned problems we sought for alternative approach to the issue of OSL dating, so we concentrated on the fine grains. Fine grain quartz was also relatively dim and only IRSL signal from fine grain polymineral fraction was sufficient to obtain absorbed dose estimates. We made the measurements on 6-12 $\mu \mathrm{m}$ fraction extracted by means of the sedimentation process in a water column. Samples were extracted from the sediment depth range between $80-750 \mathrm{~cm}$ which, basing on paleomagnetic data, should cover the period up to ca. $150 \mathrm{ka}$.

\section{Extraction of fine grains (6-12 $\mu \mathrm{m})$ from the lake sediments}

First the material was sieved through a $45 \mu \mathrm{m}$ mesh. After sieving $150 \mathrm{mg}$ of the sample (diameter less than $45 \mu \mathrm{m}$ ) was added to a $250 \mathrm{ml}$ beaker with $200 \mathrm{ml}$ deionised water. The suspension was stirred and after 15 minutes of sedimentation carefully decanted to a second clean beaker. The decanted suspension contained grains with diameter below $12 \mu \mathrm{m}$. To get rid of the fraction below $6 \mu \mathrm{m}$, decanted solution was stirred again and after 20 minutes the fraction $6-12 \mu \mathrm{m}$ was settled on the beak- 


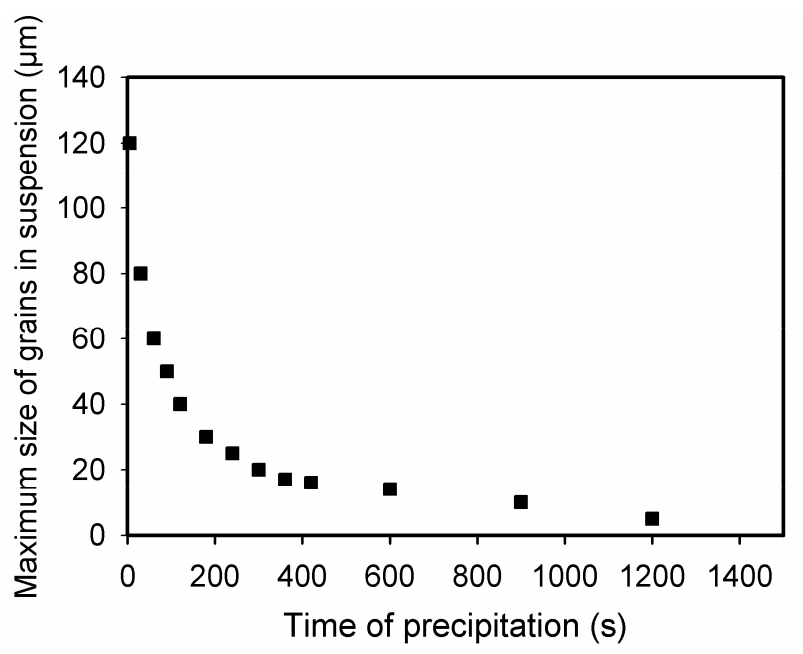

Fig. 2. A relation between precipitation time and the size of largest grains remaining in water suspension at a certain depth in the water column.

ers bottom. Finally suspension containing grains below $6 \mu \mathrm{m}$ was carefully decanted. Fig. 2 show experimental results of precipitation of mineral grains in a water column.

After this extraction grains were treated with the $15 \%$ solution of fluosilicic acid for 24 hours. To establish the duration of the fluosilicic acid treatment sufficient for removing feldspar grains an experiment with different etching times was carried out. Results of this experiment are shown in Fig. 3. Time necessary to dissolve feldspar grains is about 24 hours. The remaining grains are the fine fraction quartz.

Subsequently, the grains were rinsed with a weak solution of hydrochloric acid and distilled water to remove fluoric components. Cleaned grains were suspended in $50 \mathrm{ml}$ of alcohol and $2 \mathrm{ml}$ of the suspension was pipetted to a flat-bottom test-tube with an aluminium disk placed on the bottom. The grains settled on the disk surface and after evaporation of alcohol, the disks with a single layer of fine grains (quartz or polymineral) were ready for IRSL or OSL measurements.

\section{OSL MEASUREMENTS}

An automated Daybreak TL/OSL reader of type 2200 (Bortolot, 2000) were used for OSL measurements. The reader uses blue diodes $(470 \pm 4 \mathrm{~nm})$ for stimulation and delivers about $60 \mathrm{~mW} / \mathrm{cm}^{2}$ at the sample position. The reader is fitted with a ${ }^{90} \mathrm{Sr} /{ }^{90} \mathrm{Y}$ beta source delivering about $70 \mathrm{mGy} / \mathrm{s}$ to quartz at the sample position. The reader uses infrared diodes $(880 \pm 4 \mathrm{~nm})$ for IRSL measurements and delivers about $68 \mathrm{~mW} / \mathrm{cm}^{2}$ at the sample position for infrared stimulation.

To select the optimum preheat temperature the preheat plateau test was carried out. Aliquots made from the same sample have been subjected to different preheat temperatures during measurements of equivalent absorbed dose by SAR method (Murray and Roberts, 1998). Results are presented in Fig. 4. They show a plateau of apparent equivalent dose $(E D)$ values between $200-270^{\circ} \mathrm{C}$. Following this test the preheat temperature was set at $220^{\circ} \mathrm{C}$.

Finally, the measurement protocol for Daybreak TL/OSL readers type 1150 and 2200 was established basing on standard SAR protocol with double excitation (Murray and Roberts, 1998; Murray and Wintle, 2000), the first one with IR light and the second with the visible light, blue or green depending on the reader used.

The combined IRSL/OSL single aliquot regenerative (SAR) protocol used in this work comprised:

1) Irradiation with the regenerative beta dose $D_{i}$

2) Preheat at the temperature $T_{p h}$ for the time $t_{p h}$

3) Infrared stimulation at the temperature $T_{\mathrm{IRSL}}$ for time $t_{\mathrm{IRSL}}$
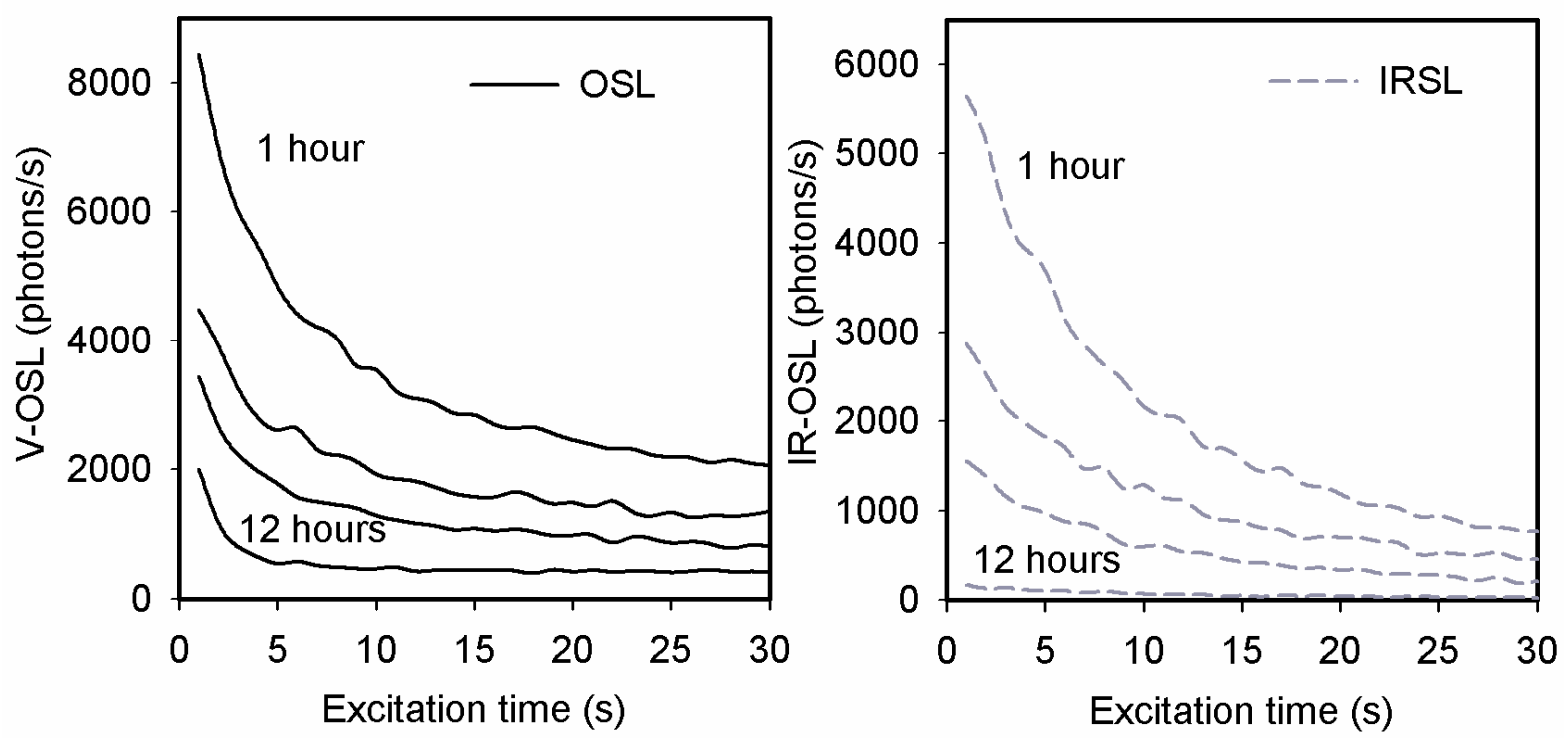

Fig. 3. Effect of etching fine grains with fluosilicic acid for 1, 2, 4 and 12 hours. OSL and IRSL stimulated luminescence glow curves are presented to show the reduction of the luminescence signal during etching. 


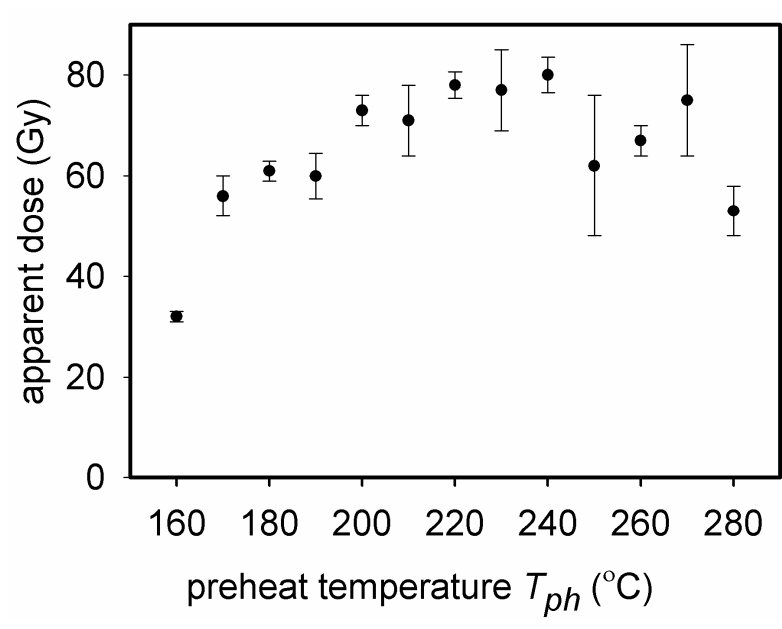

Fig. 4. Effect of changing the temperature of preheat after irradiating an aliquot with regenerative beta dose on apparent equivalent dose.

4) Visible light stimulation at the temperature $T_{\mathrm{OSL}}$, for time $t_{\mathrm{OSL}}$

5) Irradiation with test dose $D_{t}$

6) Preheat at the temperature $T_{t p h}$ for time $t_{t p h}$

7) Infrared stimulation at the temperature $T_{\mathrm{IRSL}}$ for time $t_{\mathrm{IRSL}}$

8) Visible light stimulation at the temperature $T_{\mathrm{OSL}}$, for time $t_{\mathrm{OSL}}$

Values of parameters were selected as follows:

- $T_{p h}=220^{\circ} \mathrm{C} ; t_{p h}=10 \mathrm{~s}$

- $\quad T_{t p h}=160^{\circ} \mathrm{C} ; t_{t p h}=0 \mathrm{~s}$ ('cut-off heating')

- $T_{\text {IRSL }}=60^{\circ} \mathrm{C} ; \mathrm{t}_{\mathrm{IRSL}}=200 \mathrm{~s}$

- $T_{\mathrm{OSL}}=125^{\circ} \mathrm{C} ; t_{\mathrm{OSL}}=30-100 \mathrm{~s}$ (shorter time for the blue light and longer time for the green light stimulation)

- $\quad D_{t} \approx 10 \%$ of the natural dose, but not less than 2-5 Gy. Generally results obtained on fine grain quartz extracts and on fine grain polymineral extracts using OSL showed a great aliquot to aliquot scatter and could not be used for a reliable $E D$ estimation. An example, shown in Fig. 5, was exceptionally good with respect to this problem.

The last resource was then to use fine grain polymineral aliquots stimulated with IR. The results shown in Fig. 6 are raw age estimates and age estimates corrected for anomalous fading that was substantial in these samples, amounting to $0.79 \pm 0.01$ over 6 weeks. The upper sections of lake sediments at this site were also sampled for radiocarbon dating (Piotrowska et al., 2004). In this case terrestrial pollen extracts were dated by AMS C-14 method yielding reliable results. C-14 ages were calibrated and are plotted on the same graph in Fig. 6, but they come from physically different material cored at this site. For IRSL ages about 50-60 ka luminescence signal saturated, so deeper parts of could not be dated.

The IRSL dating results are also presented in Table 1.

\section{CONCLUSION}

We have tested the single-aliquot regenerative-dose (SAR) protocol on the IR- and blue-stimulated signals from polymineral fine-grains extracted from lake sedi-

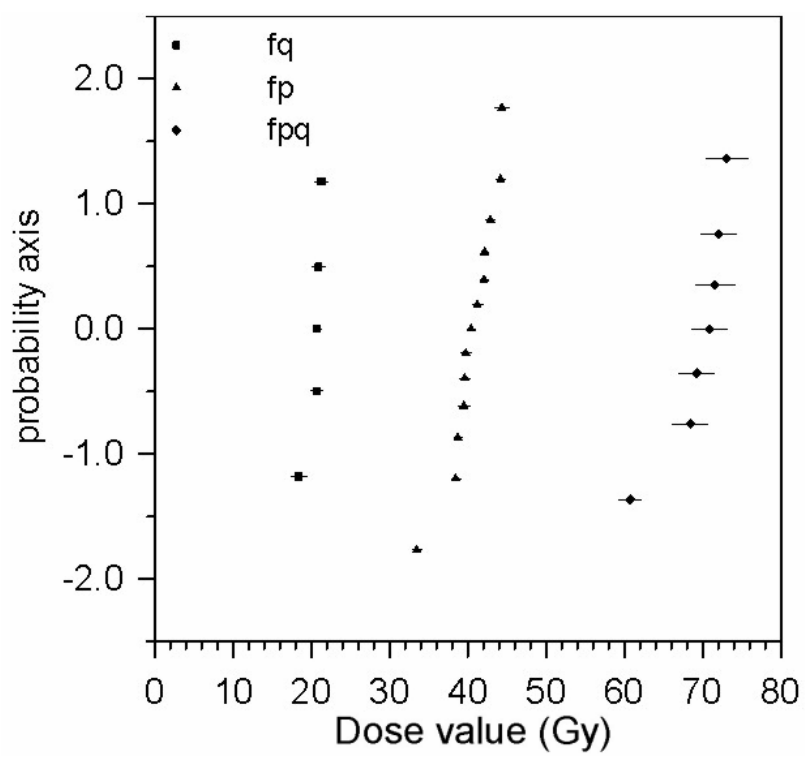

Fig. 5. A comparison of results obtained on different fractions of sample CON01 603-4 0010 158, and using different luminescence signals. From left to right: fine grain quartz stimulated with green light (fq), fine grain polymineral stimulated with IR (fp), fine grain polymineral stimulated with green light (combined IRSL/OSL) (fpq).

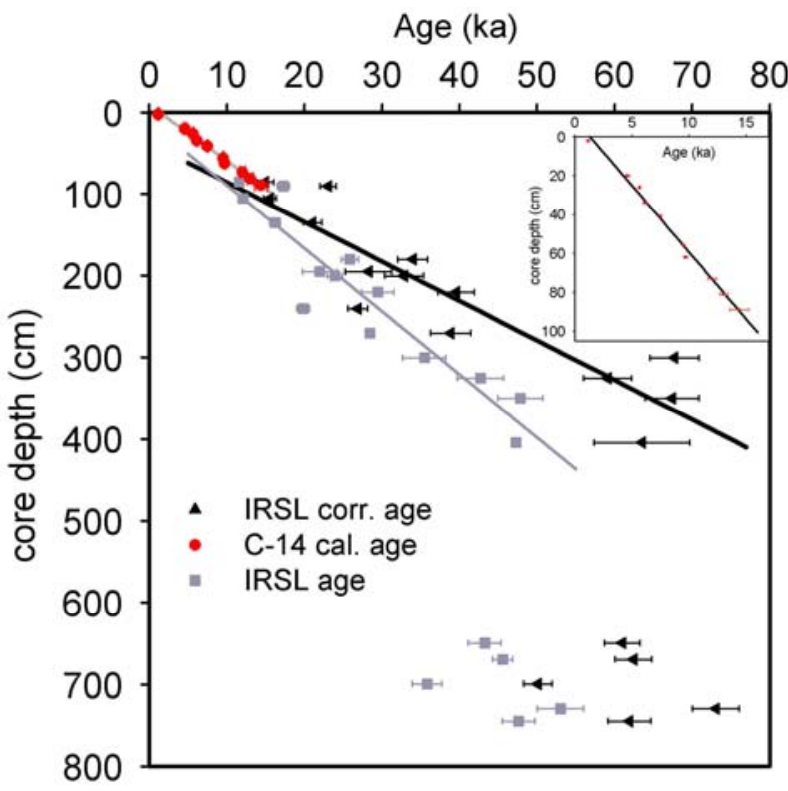

Fig. 6. Results of dating of Lake Baikal sediments. Age estimates obtained by IRSL single aliquot are shown as squares (raw results) and as triangles after anomalous fading correction applied. Calibrated C-14 ages obtained on pollen extracts from the same location (Piotrowska et al., 2004) are shown as circles. Regression lines are used to estimate average sedimentation rates: in the upper part, basing on $\mathrm{C}-14$, sedimentation rate is $6.86 \pm 0.21 \mathrm{~cm} / \mathrm{ka}$, in the lower part, basing on corrected IRSL results $-4.83 \pm 0.60 \mathrm{~cm} / \mathrm{ka}$. The inset shows $C-14$ calendar ages for the upper $100 \mathrm{~cm}$ section of sediments. 
Table. 1. Results of dating of Lake Baikal sediments. Water content, ED values and age estimates obtained by IRSL single aliquot before and after anomalous fading correction applied.

\begin{tabular}{lccccc}
\hline $\begin{array}{l}\text { Sample } \\
\text { number }\end{array}$ & $\begin{array}{c}\text { Depth } \\
(\mathbf{c m})\end{array}$ & $\begin{array}{c}\text { Water content } \\
\text { (\% dry mass) }\end{array}$ & $\begin{array}{c}\text { Equivalent dose } \\
(\text { Gy) }\end{array}$ & $\begin{array}{c}\text { IRSL corr. age } \\
\text { (ka) }\end{array}$ & $\begin{array}{c}\text { IRSL age } \\
\text { (ka) }\end{array}$ \\
\hline 168 & 85.5 & 82.7 & $41.3 \pm 2.4$ & $15.0 \pm 1.1$ & $11.6 \pm 0.5$ \\
167 & 90.5 & 86.7 & $63.8 \pm 1.2$ & $23.1 \pm 1.0$ & $17.3 \pm 0.8$ \\
164 & 105.5 & 86.6 & $43.4 \pm 2.3$ & $15.6 \pm 0.8$ & $12.1 \pm 0.5$ \\
158 & 135.5 & 80.2 & $54.7 \pm 1.9$ & $21.1 \pm 1.2$ & $16.2 \pm 0.7$ \\
149 & 180.5 & 95.5 & $82.1 \pm 2.8$ & $34.0 \pm 1.9$ & $25.9 \pm 1.1$ \\
357 & 195.5 & 95.5 & $79.1 \pm 1.1$ & $28.3 \pm 3.0$ & $22.0 \pm 2.2$ \\
369 & 200.5 & 73.5 & $101.7 \pm 7.7$ & $32.9 \pm 2.5$ & $24.0 \pm 1.0$ \\
352 & 220.5 & 75.0 & $109.8 \pm 6.3$ & $39.6 \pm 2.3$ & $29.5 \pm 2.1$ \\
348 & 240.5 & 67.7 & $100.4 \pm 3.3$ & $26.9 \pm 1.3$ & $19.9 \pm 0.8$ \\
388 & 270.5 & 61.6 & $116.3 \pm 4.3$ & $38.9 \pm 2.6$ & $28.4 \pm 0.2$ \\
382 & 300.5 & 177.2 & $96.3 \pm 3.2$ & $67.7 \pm 3.2$ & $35.5 \pm 2.8$ \\
377 & 325.5 & 117.6 & $130.5 \pm 5.3$ & $59.1 \pm 3.1$ & $42.7 \pm 3.0$ \\
326 & 350.0 & 145.1 & $128.9 \pm 5.8$ & $67.4 \pm 3.5$ & $47.8 \pm 2.9$ \\
335 & 404.5 & $125.9 \pm 9.2$ & $63.5 \pm 6.2$ & $47.3 \pm 0.3$ \\
228 & 649.5 & 159.4 & $61.0 \pm 2.3$ & $43.3 \pm 2.1$ \\
224 & 669.5 & 62.0 & $149.5 \pm 4.3$ & $62.4 \pm 2.4$ & $45.6 \pm 1.3$ \\
218 & 699.5 & 65.1 & $142.4 \pm 3.9$ & $50.1 \pm 1.8$ & $35.8 \pm 1.9$ \\
212 & 729.5 & $172.2 \pm 0.2$ & $73.1 \pm 3.0$ & $53.0 \pm 3.0$ \\
189 & 744.5 & 67.5 & $159.9 \pm 1.1$ & $61.9 \pm 2.8$ & $47.6 \pm 2.1$ \\
\hline
\end{tabular}

ments. The initial attempts to date coarse quartz grains failed because such grains were very sparse and dim. Obtained results on fine grain quartz extracts and on fine grain polymineral extracts using OSL showed a great aliquot to aliquot scatter and could not be used for a reliable $E D$ estimation. Luminescence signals from fine grain polymineral aliquots stimulated with IR were corrected for anomalous fading and yielded age estimates. The comparison of IRSL dates with radiocarbon dates obtained for the upper section of lake sediments show similar sedimentation rates of $4.83(60) \mathrm{cm} / \mathrm{ka}$ and $6.86(21) \mathrm{cm} / \mathrm{ka}$ respectively.

\section{REFERENCES}

Adamiec G and Aitken M, 1998. Dose-rate conversion factors: update. Ancient TL 16: 37-50.

Bortolot VJ, 2000. A new modular high capacity OSL reader system. Radiation Measurements 32(5-6): 751-757, DOI 10.1016/S13504487(00)00038-X.

Catto N, Prokopenko A and Chlachula J, 2001. Lake Baikal and surrounding regions. Quaternary International 80-81: 1-2, DOI 10.1016/S1040-6182(01)00014-3.

Colman SM, Peck JA, Karabanov EB, Carter SJ, Bradbury JP, King JW and Williams DF, 1995. Continental climate response to orbital forcing from biogenic silica records in Lake Baikal. Nature 378 (6559): 769-771, DOI 10.1038/378769a0.

Duller GAT, 2004. Luminescence dating of Quaternary sediments: recent advances. Journal of Quaternary Science 19(2): 183-192, DOI 10.1002/jqs. 809 .

Hutchinson DR, Golmshtok AJ, Zonenshain LP, Moore TC, Scholz CA, and Klitford KD, 1992. Depositional and tectonic framework of the rift basins of Lake Baikal from multichannel seismic data. $\mathrm{Ge}$ $\begin{array}{llll}\text { ology } 20(7): & 589-592, & \text { DOI } & 10.1130 / 0091-\end{array}$ 7613(1992)020<0589:DATFOT $>2.3 . C O ; 2$.

Karabanov EB, Prokopenko AA, Williams DF and Khursevich GK, 2000a. A new record of Holocene climate change from the bottom sediments of Lake Baikal. Palaeogeography, Palaeoclimatology, Palaeoecology 156 (3-4): 211-224, DOI 10.1016/S00310182(99)00141-8.

Karabanov EB, Propenko AA,Williams DF and Khursevich GK, 2000b. Evidence for mid-Eemian cooling in continental climatic record from Lake Baikal. Journal of Paleolimnology 23(4): 365-371, DOI 10.1023/A:1008188100542.

Kuzmin MI, Williams DF, Logatchev NA, Colman S, Khakaev BN, Kawai T, Hearn P, Horie S, Pevzner LA, Bukharov AA, Fialkov VA, 1993. The Bakal Drilling Program: scientific objectives and recent results. Russian Geology and Geophysics 34: 3-11.

Kuzmin MI, Karabanov EB, Prokopenko AA, Gelety VF, Antypin VS, Williams DF and Gvozdov AN, 2000. Sedimentation processes and new age constraints on rifting stages in Lake Baikal: results of deep-water drilling. International Journal of Earth Sciences 89(2): 183-192, DOI 10.1007/s005310000090.

Minoura K, 2000. Lake Baikal: a Mirror in Time and Space for Understanding Global Change Processes. Amsterdam, Elsevier: 332 pp.

Murray AS and Roberts RG, 1998. Measurement of the equivalent dose in quartz using a regenerative-dose single-aliquot protocol. Radiation Measurements 29(5): 503-515, DOI 10.1016/S13504487(98)00044-4.

Murray AS and Wintle AG, 2000. Luminescence dating of quartz using an improved single-aliquot regenerative-dose protocol. Radiation Measurements 32(1): 57-73, DOI 10.1016/S1350-4487(99)00253$\mathrm{X}$.

Murray AS and Olley JM, 2002. precision and accuracy in the optically stimulated luminescence dating of sedimentary quartz: a status review. Geochronometria 21: 1-16.

Piotrowska N, Bluszcz A, Demske D, Granoszewski W and Heumann $\mathrm{G}, 2004$. Extraction and radiocarbon dating from pollen from lake Baikal sediments. Radiocarbon 46(1): 181-187.

Prokopenko AA, Kuzmin MI, Karabanov EB and Williams DF, 2001a. Response of the Lake Baikal sedimentary record to Heinrich catastrophic events in the North Atlantic over the past 80,000 years. Doklady Earth Sciences 379(6): 672-678.

Prokopenko AA, Karabanov EB, Williams DF, Kuzmin MI, Shackleton NJ, Crowhurst SJ, Peck JA, Gvozdkov AA and King JW, 2001b. Biogenic silica record of the Lake Baikal response to climatic forcing during the Brunhes. Quarternary Research 55(2): 123-132, DOI 10.1006/qres.2000.2212.

Prokopenko AA, Williams DF, Karabanov EB and Khursevich GK, 2001c. Continental response to Heinrich events and Bond cycles in sedimentary record of Lake Baikal, Siberia. Global and Planetary Change 28(1-4): 217-226, DOI 10.1016/S0921-8181(00)00074-6.

Prokopenko AA, Karabanov EB, Williams DF, Kuzmin MI, Khursevich GK and Gvozdkov AA, 2001d. The detailed record of climatic events during the past 75,000 yrs BP from the Lake Baikal drill core BDP-93-2. Quaternary International 80-81: 59-68, DOI 10.1016/S1040-6182(01)00019-2. 